per head of qualified staff. Among Government research institutions may be mentioned the Physikalisch-Technische Bundesanstalt, which conducts research on standards of physical quantities and on equipment, for example, where safety is involved, and the Bundesanstalt für Mechanische und Chemische Materialprüfung.

There is no exact equivalent in Germany of the Royal Society, the body most nearly corresponding to it in pre-war days, the Deutsche Akademie der Wissenschaft in Berlin, being now under the control of the Fast German Government. There are, however, four academies of science in Western Germany ; and, with the founding of the Johannes Gutenberg University at Mainz in 1946 and of the Free University of Berlin in 1948, and the conversion, in 1945, by addition of a humanistic faculty, of the College of Technology, Berlin-Charlottenburg, into the Technische Universität, Berlin, there are now in the Federal Republic of Western Germany and the Western Sector of Berlin sixteen universities, eight 'Technische Hochschulen' (colleges of technology with university status), and eight other colleges with university status but more highly specialized. The Technische Hochschulen aim to achieve a blending between teaching and applied research, and much of the undergraduate research is undertaken in industry itself. Many industrial research institutes are associated with these Technische Hochschulen, either as part of a teaching department or as separate research institutions.

At the end of the Second World War the German patent system had ceased to exist; but after protracted discussions a Western German patent office was re-established in October 1948, moving later to new premises in Munich, and in 1953 the number of patent applications was about 7 per cent higher than in the whole German Reich in 1938, the trend being towards $a$ further increase. The emphasis on applied research is growing. Even in general terms this is an impressive achievement; and, of all the achievements in particular fields that are summarized in the review, it is difficult to select examples that illustrate more emphatically the extent to which Western Germany is prepared to make the scientific research effort upon which to-day the economic and political strength of any country depend. It might be added, however, that Western Germany can again supply the bulk of its own requirements for scientific instruments and that these are finding a growing market abroad, that the Institute of Radiation and Nuclear Physics at the University of Bonn plans to instal a $30-\mathrm{MeV}$. synchro-cyclotron, that there are estimated to be eight thousand ultrasonic generators in Western Germany, and that there has been intensive development of the electron microscope which is widely used as a research tool. In electrotechnology there have been notable developments in power technology, in the field of heavy equipment, in electrical instruments of all kinds and in electronics, particularly the development of computers.

In mechanical engineering the traditional interest in machine-tool design has been maintained, and major developments are proceeding in railway transport. Gas turbines are being investigated for heavy road vehicles and stationary power plants, and extensive use of newly developed building aids and techniques has enabled the building industry to achiove a building-rate second only to that of Sweden. Much attention has been given to road research, while in chemical industry the Gelsenkirchen firm,
Bergwerke A.G., has commenced production of dicyclopentadiene based on raw benzole, and the Krupp Kohlenchemie G.m.b.H. the Fischer-Tropsch synthesis of hard paraffins. Rheinpreussen A.G. has extended its plant for propyl and butyl alcohol to a capacity of ten thousand tons annually, and Farbenfabriken Bayer, Leverkusen, is continuously improving its methods of producing dyestuff intermediates and general textile chemicals, including preservatives, detergents and emulsifiers, and is taking a great interest in automatic processing. Germany now claims second place in world plastics production, and a new research centre at Darmstadt is investigating the structure of plastics and setting up methods of testing. In the biological and medical sciences the impact of new physical techniques is evident, and some of the most significant researches are those on the fundamental chemical processes of cell metabolism, biochemical mechanisms and chemotherapeutics. Much effort is directed to the solution of Germany's difficult agricultural problems, and particular attention has been paid to soil humus, potato cultivation and systemic insect. icides.

\section{ELECTRON MICROSCOPY OF FIBRES}

$\mathrm{D}$

URING January 3-4 the Electron Microscopy Group of the Institute of Physics held what was originally intended to be a small specialist conference on the electron microscopy of textile and other industrial fibres, in the Department of Textile Industries of the University of Leeds. The response, in attendance and papers offered, showed that the experiment was amply justified. In all, more than sixty delegates, eight from overseas, attended, and eighteen papers were read and discussed. There were throe half-day sessions, devoted to techniques, protein fibres and cellulose fibres, respectively.

In the first session O. C. Wells (Cambridge) described the scanning electron microscope developed at Cambridge, and gave examples of its use for studying fibre surfaces. Whether the scanning microscope or the reflexion microscope (which was used by $J$. A. Chapman (Manchester) in a study of abraded nylon fibres) will ultimately 'corner' this particular field was the subject of much speculation ; neither is yet capable of the resolution of the conventional transmission instrument, but each has certain advantages. On the whole, opinion seemed to be that the added complication of the scanning instrument would, at present, prevent its competing effectively with the other, but further developments will be eagerly awaited by microscopists.

Replication techniques were discussed by D. G. Drummond (Manchester) and by L. Oster, J. Sikorski and H. J. Woods (Leeds). Both schools find twostage replicas most satisfactory in practice; Drummond has been working with the polystyrene/carbon process ${ }^{1}$, but the Leeds workers still favour their silver/SiO technique, which they are using to study merino wool and nylon surfaces. Drummond stressed the desirability of reducing preparatory techniques to a routine capable of being followed by unskilled assistants; but the Leeds team seemed to imply that this was crying for the moon, since in their experience replication is an art which can only be learned by experience. 
Ultra-thin sectioning is at last becoming a major tool in fibre microscopy, and a number of papers were devoted to investigations in this field. A. O. T. Charles and J. Sikorski (Leeds) havo studied the polymeriza. tion of embedding methacrylates, an important process in the preparation of specimens for sectioning; they discussed the advantages and drawbacks of the technique they favour, namely, polymerization by ultra-violet light. P. Chippendale (Manchester) showed sections of wool, rayon and nylon fibres and illustrated how skin and core effects can sometimes be detected in the man-made fibres. Although some details of the cellular constitution of the cortex could be seen in his wool sections, the results emphasized that normal wool has only slight variations in electron density between histological components in the cortex. G. E. Rogers (Cambridge) presented two papers which described what were technically the most beautiful micrographs shown at the conference. His sections of the wool follicle, although enormously superior in resolution, could be compared for clarity with the best results of the histologists using light microscopes, who seem to be left with few distinctive tools other than stains and the polarizer. Enthusiasm for sectioning must, however, be tempered by the fact that the examina. tion of normal mature natural fibres by this technique has not yet produced any very remarkable results, and it remains to be seen whether the argument, that sectioning is the only correct technique because it does not involve degradation, is still valid. A point of view which found support was that the use of sectioning or disintegration in conjunction with controlled chemical treatments is still one of the most fruitful fields of investigation.

In the second session Sikorski and Woods pointed ont the difficulty of reconciling the macrofibrillar type of structure observed in the follicle of a wool fibre with the occurrence of extended microfibrillar sheets in disintegrated fibres. They suggested that keratinization might involve the stabilization of a microfibrillar texture which is not yet obvious in the matrix regions of the cortical cell in the follicle, and the uniplanar linking together of the microfibrils to form sheets. They reported that different methods of attacking the disulphide links in keratin (for example, by reduction or oxidation) may lead to distinctive disintegration products when specimens are prepared for examination by the electron microscope. M. S. C. Birbeck and E. H. Mercer (London) described sections of hair in their study of the cuticle layer. They now believe, on the basis of histochemical experiments, that the endocuticle is non-keratinous in character; they also emphasized the importance of the cell membranes both in the cuticle and the cortex of the fibre. An interesting suggestion was that in human hair, where the cuticle cells have large overlaps, the epicuticle seems to be tucked in beneath the scale which it is covering; this feature is less obvious in wool fibres.

D. Burton, R. Reed and M. J. Wood (Leeds) discussed the hydrothermal shrinkage of leather, a phenomenon of great technological importance in the control of leather manufacture. In the early stages of hydrothermal treatment, tanned collagen fibrils swell and assume a helical form, while the crossstriations come closer together. Similar structures, with left- or right-handed twist, also occur during the heat treatment of native collagen fibrils. The fibril is therefore considered to be a cross-helical array of polypeptide chain bundles, these being of variable chomical composition and hence sensitivity towards heat. 'Tanning forms cross-links between the two helical arrays, while shrinkage involves the relative movement of the cross-helical structures.

K. M. Rudall (Leeds) showed pictures of the thin ribbon-like units of the ootheca of the praying mantis. Structurally, these protein sheets are important in that they possess a modified $\alpha$-type structure with preferred orientation in the transverse plane; although the polypeptide chains are parallel to the length of the ribbon, a feature of the electron micrographs is the appearance of striations inclined to the length at an angle of approximately $22^{\circ}$. A. B. Meggy and J. Sikorski (Leeds) described microcrystals of the two forms of polyglycine [see also p. 326 of this issue] ; the most notable micrographs showed that polyglycine II crystallizes in hexagonal laminæ, in agreement with the trigonal structure proposed recently by Crick and Rich2. Growth spirals are observed in the crystals, and the growth steps correspond roughly, but not exactly, with the mean chain-length. Although both forms of polyglycine can absorb considerable quantities of dye (for example, orango II), there is no direct evidence either from X-ray or electron microscope studies as to where the dye is located in the structure.

The final session started with a paper by E. Frei and R. D. Preston (Leeds), who showed micrographs of serial sections of conifer wood tracheids, in which the spiral angle of the microfibrils could be observed. They confirmed that the structure of the various layers in the cell wall is substantially the same as had been suggested by previous $\mathrm{X}$-ray and polarization microscope results; in particular, the basic structure of the outer layer of the secondary wall is a flat spiral, although microfibrils running at a steeper pitch are also present. Somewhat similar results were obtained by H. W. Emerton (Kenley), who is concerned with the outer layers of the cell wall because of their importance in connexion with paper-making. In his striking pictures of softwood tracheids obtained with the reflexion microscope, however, he observed only the macrofibrils, and this provoked a discussion as to why his severely treated beaten fibres should show such remarkable macrofibrils, whereas the (presumably) more gently treated material of Frei and Preston should give remarkably clear microfibrils. There is a curious antiparallel here with the results previously mentioned for keratin, where disintegration was claimed to lead to microfibrils and sectioning to macrofibrils. To make matters more obscure, S. Asumnaa (Stockholm) showed sections of laboratory pulps impregnated with heavy-metal atoms, in which little in the way of a fibrillar structure could be seen at all. Some of her preparations did reveal a striated structure, and there were differences attributable to the effects of various chemical treatments.

R. H. Marchessault (Marcus Hook, U.S.A.) and B. G. Rånby (Upsala) have extended the work on the hydrocelluloses produced by the action of mineral acids on cotton and wood, which reduce the microfibrils to elongated rod-like particles, and attempted to correlate the lengths of the particles with the degree of polymerization (osmotic value). A problem which they had to solve was to produce well-dispersed samples; they found sulphuric acid preferable to hydrochloric acid as a hydrolysing agent, while the concentrated acid, low-temperature technique of Mukherjee and Woods ${ }^{3}$ gave better dispersions than the dilute acid, high-temperature process of Ranby and Ribi". Sulphation of the surface 
layers of the particles was suggested as a reason for this.

A long paper on the fine structure of viscose rayon was presented by $\mathrm{P}$. Kassenbeck (Paris). Among other topics, he considered the possibility of obtaining crimped fibres by bilateral heterogeneity, the influence of spinning conditions on the fine structure, and the question of a surface skin on the fibres. He suggested that the skin usually observed in the light microscope is covered by another very thin superficial layer. Can we expect now another battle of nomenclature?

Much credit for an interesting and stimulating conference is due to Dr. Sikorski, the local organizer.

'Bradley, D. E., Inst. Phys. Electron Micr. Group Conf., Glasgow $(1955)$.

'Crick, F. H. C., and Rich, A., Nature, 176, 780 (1955).

${ }^{3}$ Mukh rjee, S. M., and Woods, H. J., Biochim. Biophys. Acta, 10 $4: 99(1953)$.

${ }^{4}$ Rånby, B. G., and Ribi, E., Acta Chem. Scand., 3, 649 (1949).

\section{PHYSICS OF ATMOSPHERIC CLOUDS}

$\mathrm{D}$ URING January 4-5 the Physical Society and the Royal Meteorological Society held a joint corference on cloud physics in the Department of Meteorology, Imperial College of Science and Technology, London. It was so arranged that on each day four speakers outlined recent developments in a particular branch of the subject; unusually generous periods were allotted, and needed, for discussion.

On the first daky Mr. B. J. Mason (Imperial College) gave a short introductory talk on the scope of the cloud physics to be reviewed, which extended from the laboratory studies of the microphysical processes affecting the formation and growth of cloud particles, to the properties of the extensive cloud systems responsible for cyclonic rains. He was followed by Dr. C. Junge (United States), who spoke on the nuclei of atmospheric condensation, a subject on which much of our present knowledge is due to Dr. Junge's own researches, mostly made since the Second World War, first in Germany and more recently in the United States. He described how the composition and size distribution of the particles of atmospheric aerosol have been investigated, over the enormous range of sizes from a radius of about $10^{-7} \mathrm{~cm}$. to about $10^{-3} \mathrm{~cm}$. The smaller of these particles are the most numerous, usually occurring in concentrations of about $10^{4} / \mathrm{cm}^{3}$, and are those predominantly precipitated in conventional nucleus counters (the 'Aitken nuclei'). Particles with diameters exceeding about $10^{-5} \mathrm{~cm}$. are usually found in size distributions characterized by the relation $\mathrm{d} n / \mathrm{d}(\log r)=$ const. $/ r^{3}$, where $\mathrm{d} n$ is the concentration of particles in the range of radius $d r$. The largest particles, the giant nuclei, with radius exceeding $10^{-4} \mathrm{~cm}$. , occur in concentrations of less than $1 / \mathrm{cm} .^{2}$, but are important in cloud formation, for they produce a small proportion of unusually large cloud droplets which may readily grow to raindrops by settling through and sweeping up the remainder (the 'coalescence process' of rain formation). The giant nuclei are composed mainly of sea-salt derived from sea-spray, and have been extensively sampled by Dr. A. H. Woodcock (United States) and Dr. H. Dessens (France), who also took part in the conference. Dr. Junge discussed the composition of the somewhat smaller nuclei, which produce the bulk of cloud droplets, and showed that the important constituents are ammonium and sulphate radicals $\mathrm{He}$ particularly emphasized the importance of generating processes and of coagulation and precipitation processes in maintaining the characteristic size-distributions, and the need for more study of the trace materials present in the air in similar concentrations, but in the gas phase. The discussion became a debate on the proportions of cloud droplet nuclei which are produced by sea spray; the general opinion was that it is their size, rather than number, which makes the sea salt nuclei important.

Dr. H. Weickmann (United States) reviewed information on the constitution of non-precipitating clouds, dividing them for this purpose into stratified and convective clouds. He gave special attention to the relations between the droplet size distribution, the total concentration of condensed water, and the visibility in clouds. He mentioned that the local conversion of supercooled clouds into crystal clouds by seeding is useful as a kind of marking which gives insight into ordinarily invisible turbulent and other air motions in the clouds. Illustrations of the peculiar crystal forms found in ice clouds were drawn from a remarkable series of high-altitude flights in an opencockpit aircraft which Dr. Weickmann made in Germany during the Second World War. He finally mentioned the iridescent colours, and by inference the droplet constitution, of the rare stratospheric mother-of-pearl clouds, the temperature of which is thought usually to be as low as $-80^{\circ} \mathrm{C}$. This provoked discussion and alternative inferences from the physicists, who now believe that liquid water freezes spontaneously at about $-40^{\circ} \mathrm{C}$.

In the afternoon of the first day, Mr. B. J. Mason, speaking rapidly, gave an impressive account of the growth of research upon the nucleation of supercooled water-the initiation and the growth of ice crystals. He discussed the role of homogeneous and heterogeneous nucleation of supercooled droplets, and concluded that in the atmosphere they have predominant importance at temperatures near and below $-40^{\circ} \mathrm{C}$., and above about $-30^{\circ} \mathrm{C}$., respectively. He supposed that the effective particles at the higher temperatures are wind-raised silicates. Much more efficient ice nuclei can be made from the iodides of lead and silver, whereas practically all other chemicals can be shown to be inactive. Mr. Mason then reviewed the growth of ice crystals by condensation, and remarked especially that the pre. ferred habit changes with temperature: down to $-4^{\circ}$ C. hexagonal plates predominate; between $-4^{\circ} \mathrm{C}$. and $-8^{\circ} \mathrm{C}$., and below about $-20^{\circ} \mathrm{C}$., prisms occur; while between about $-8^{\circ} \mathrm{C}$. and $-20^{\circ} \mathrm{C}$. plates and stars are found. In the laboratory: crystals of startling shape have been grown by varying the temperature: for example, long prisms have been made to sprout upwards from the corners of a hexagonal plate. In the discussion, some speakers challenged the view that only the temperature controls these changes in crystal habit, and Prof. J. D. Bernal doubted if they could be explained by considering only equilibrium states. Dr. Dessens mentioned a small sausage-shaped (presumably organic) type of particle which has been identified as an active ice nucleus in the atmosphere at temperatures below $-12^{\circ}$ C. Mr. J. S. Turner (Australia) announced a recent experiment which shows that the loss of nucleating activity to which silver iodide smokes are subject in the daylight does not occur at night.

Dr. R. Braham (United States) reviewed the physics of precipitation mechanisms, and emphasized 